\title{
Rodríguez Álvarez, María de los Ángeles, Yo, Gregorio Torres Quintero, Archivo Histórico del Municipio de Colima, Tierra de Letras, Colima, 2014, 614 pp., ISBN: 978-607-701-026-5
}

\section{Omar Alejandro Pérez Cruz*}

Hace casi diez años que tuve el primer contacto con "Mara" (como cariñosamente conocemos a la doctora María de los Ángeles Rodríguez Álvarez) como asesora y con la tentación de dirigir mi tarea investigadora de estudios doctorales hacia un derrotero como lo es la historia. Mara dedicó varias mañanas a mostrarme cómo se revalora el pasado, una época y sus circunstancias. A la par, me enseñaba las finas y gruesas puntadas que conlleva el complejo tejido de la historiografía.

En distintas ocasiones la lectura del libro Yo, Gregorio Torres Quintero me planteó reflexiones sobre la creación humana y sus indeterminaciones en el sentido de Castoriadis.

Así, la reconocida historiadora nos presenta en este libro el análisis de una biografía. No es, sin embargo, un recorrido cronológico el que inspecciona esta obra, sino que devela el contexto personal y la época en que se gestó una de las figuras educativas que contribuyó a una de las más importantes transformaciones experimentadas en el sistema educativo mexicano del siglo xx: la vida y obra de Gregorio Torres Quintero.

La finalidad de Rodríguez Álvarez es reconstruir la memoria de una existencia; para ello entabla entrañables diálogos de Torres Quintero, por medio de cartas, documentos, archivos y fragmentos de sueños y frustraciones que el maestro dejó entrever en sus escritos.

En el preludio de este recorrido historiográfico, Rodríguez Álvarez presta sus recuerdos para mostrarnos las veces que transitó por los simbólicos sitios donde se encontraban los datos que había de recuperar para esbozar este libro.

* Doctor en Ciencias Sociales, Profesor-investigador de la Universidad de Colima, correo electrónico: omar_perez@ucol.mx 
Menciona las ocasiones en que tuvo el referente del ilustre maestro frente a ella y no se percató de su presencia, como en el caso de la Universidad Pedagógica Nacional del Ajusco, donde la biblioteca lleva el nombre del maestro colimense. La autora ya había coordinado un libro sobre los escenarios, actores y procesos de la educación en Colima durante los siglos XIX y XX'1, pese a ello, no atinaba en retomar las pesquisas sobre Torres Quintero, además, explica que el prócer de la educación estuvo ligado a su vida personal, ya que tuvo contacto con su madre en su paso por la escuela de las Adoratrices ${ }^{2}$ en Colima.

La obra de Rodríguez Álvarez fue desarrollada con un minucioso trabajo que remontó 11 archivos históricos en un recorrido por Colima, Ciudad de México, Estado de México, Jalisco y Michoacán; así como entrevistas y documentos personales que donó la parentela de Torres Quintero. La articulación de los 11 capítulos, las 614 páginas y las 934 notas imponen a primera vista, y la impresión se amplía cuando nos adentramos y disfrutamos del pletórico contacto con los archivos. No pretendo exponer linealmente los 11 capítulos abordados, esto para dar espacio a los matices que encontré en la obra completa.

El resultado es una biografía novelada que nos muestra un ser humano apasionado de su labor, comprometido con su tiempo y venturoso en las circunstancias que le tocó vivir. La lectura busca llegar a públicos más amplios que reflexionen sobre su propio quehacer y posición ante la vida.

Sobre el campo de la biografía de Gregorio Torres Quintero es necesario decir, primero, que no es un derrotero nuevo en México, pero tampoco muy nutrido y con pinceladas claras sobre sus interpretaciones. Un rápido recorrido por sus sendas puede servir para vislumbrar esta nueva contribución de Rodríguez Álvarez.

Ante la primera impresión, el lector puede tener cierto desconcierto sobre la frescura del tema, y puede cuestionar la pertinencia de escribir sobre Gregorio Torres Quintero, ya que la misma autora argumenta que ella misma creyó que ya habían sido vastos los escritos sobre este personaje. De este modo, la historiadora muestra su propia innata curiosidad, convirtiendo en objeto de estudio un personaje rico en interpretaciones. En su oficio de historiadora procuró adelantarse a las inquietudes de los lectores, ávidos de nueva información sobre el maestro. Así, la relevancia de esta obra radica en dos aspectos que entrelaza hábilmente: el oficio de historiadora y la redacción creativa que da matices novelados a la biografía. Al respecto realicemos algunas apreciaciones.

1 Rodríguez Álvarez, María de los Ángeles (coord.), Escenarios, actores y procesos. La educación en Colima durante el siglo XIX y primeras décadas del XX, Universidad de Colima, Colima, 2007.

2 Colegio del Sagrado Corazón, dependiente del Convento de las Adoratrices del Sagrado Corazón de Jesús. Colegio con más de 120 años de existencia en Colima, actualmente denominado Instituto Cultural de Colima. 
El oficio de historiadora le permitió a Rodríguez Álvarez aplicar la historiografía, donde se enlazan estrategias metodológicas para generar y organizar la información que liga a momentos y coyunturas históricas, y que produce los argumentos, enfoques e interpretaciones que relata la investigadora. El arte de escribir historia es un campo indeterminado, como lo señala Castoriadis, por lo que si algo aporta la autora es reunir la información y dejar que sea el propio Gregorio Torres Quintero quien relate su vida. Esto se debe a la copiosa información proporcionada en el libro y que surge de las palabras rescatadas de sus libros, escritos y cartas.

Sobre el aspecto de la redacción creativa y los matices novelados de la biografía es imprescindible recodar que el género biográfico es ejemplo claro de las indeterminaciones de la historia. Toda biografía es una historia en particular; es un trozo de la historia humana expuesto a la mirada curiosa de las personas, como una muestra de los actos humanos en un tiempo y época específica. Así, una biografía plantea el reto de adentrase en la vida particular y generar información para posibilitar el ejercicio hermenéutico de interpretar. En este campo nuevo para Rodríguez Álvarez, la historiadora se arriesga a revitalizar la imagen del maestro al aportar nuevos enfoques desde la historia, la pedagogía y la sociología.

De tal manera que nos abre la puerta para entrar a un proscenio distinto, desde el cual situarnos; $y$ aunque fue difícil encontrar la veta de su cotidianeidad o su personalidad completa, la autora traspasa ligeramente el nivel manifiesto de la realidad para localizar al hombre en su dimensión individual, poética, casi inconsciente, de sus actividades documentadas.

En este sentido, el historiador que reconstruye una biografía, como es el caso de esta obra, se enfrenta a la disyuntiva de agregar valor a lo ya escrito. ¿Cómo revalorizar? A lo que Rodríguez Álvarez explica que pretendió mostrar al Gregorio Torres Quintero humano y profesional, alejado del mito y la visión institucional.

De tal manera que, si se permite describir la nueva biografía de Gregorio Torres Quintero, podría describirla como revalorizada, y no pretendemos utilizar el término de valor en su connotación de mayor importancia o de cualidades superiores. Esta senda puede ser peligrosa y denostar comparaciones anacrónicas e innecesarias entre el pasado - principalmente cuando se trata de hombres de grandes contribuciones a la humanidad-, como es el caso de este personaje.

En este sentido, refiero el libro como una contribución que revalora la imagen del maestro colimense. Por un lado, se idearon estrategias, se aplicaron metodologías y se generó información para identificar las indeterminaciones que crearon las condiciones para abrigar nuevos sentidos. Esto sin duda es una muestra palpable del profundo contacto con el personaje, de las formas y los medios que se establecieron entre el biografiado y su entorno; lo articulado y 
lo desarticulado; las presencias, así como las ausencias que producen sentido; y los discursos que entretejen y marcan líneas de sentido para acercarse a la realidad.

Rodríguez Álvarez no buscó exponer el devenir del maestro, sino reflexionar por el inconsciente de imaginarios sociales que produjeron símbolos y sentidos en torno a Gregorio Torres Quintero.

De esta manera, la autora logra acariciar la fase humana, cálida y colmada de emociones y sentimientos, gracias al encomiable trabajo metodológico y a la sutil creatividad para redactarla. Muestra aspectos de la vida de Torres Quintero que no habían sido explorados y desdibuja la fase seria y altiva del hombre. Esto ocurre desde el primer capítulo, donde Francisco Torres (hermano y padrino) le escribe a Gregorio unas palabras con motivo de su cuarenta aniversario. Al respecto, mostramos lo que Francisco le dice a su hermano:

Querido hermano y ahijado: a tus cuarenta años, recuerdo... tu nacimiento... dedícale un recuerdo de gratitud [a nuestra madre] por los esfuerzos que hizo porque llegarás a la posición en que te encuentras. Creo que mi carta del 22 de mayo despertó tu curiosidad por saber más de nuestros antepasados y ahora me pides más datos sobre la familia de nuestro padre; quizás a la distancia te sorprendieron varios hechos (pp. 33-35).

Yo no intento disimularlo: este día me llena de la satisfacción más grande que he experimentado en mi vida. El hombre que en sus trabajos y fatigas, mira en lontananza el objeto de sus afanes, sueña en alcanzar, en llegar a donde le espera la realización de sus deseos de aquellos deseos que por tanto tiempo ha acariciado, que por tanto tiempo ha conservado encerrados, comprimidos dentro del pecho. ¡Qué hermoso, cuán satisfactorio es para el caminante a quien fatiga la sed, llegar a convencerse de que el hermoso lago que veía brillar en los confines del horizonte, ya no es, como otras veces, una de las desgarradoras ilusiones del desierto! (p. 189).

Con mi renuncia se cerró una larga etapa de mi vida dentro del Ministerio de Instrucción Pública a donde había llegado en 1898; quince años había estado en la función pública del sector educativo, además de mis tareas como profesor, básicamente, en la Normal. Podía sentirme orgulloso de haber pertenecido a esta época durante la cual produje muchas obras y libros que me proporcionaron junto con mis trabajos una buena posición económica. El haberme quedado sin trabajo de base por primera vez desde mi egreso del Liceo y ante la terrible situación que enfrentaba el país, me hacían sentir incómodo e inestable. También miraba como mis compañeros maestros sufrían durante esta década revolucionaria porque muchas veces sus salarios no eran pagados a tiempo; se retrasaban sin saber cuándo podrían recibirlos además de estar muy mal pagados; y yo, sin uno de base, era para estar intranquilo (p. 346) 
Con este breve recorrido mostramos la importancia que tiene el presente libro, toda vez que viene a completar el campo de los estudios sobre personajes ilustres de Colima y de México. Por ello se reconoce esta obra cuya historia particular se teje de manera muy fina con la historia nacional, donde las sendas recorridas por Torres Quintero no fueron sencillas, pero que finalmente permiten ser ejemplos de vida para todo lector que se acerque a este libro. 